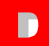

Acredited: SK No.: 60/E/KPT/2016 Website : http://ejournal.undip.ac.id/index.php/reaktor/

\author{
Reaktor, Vol. 18 No. 4, December Year 2018, pp. 235-240
}

\section{Antimicrobial Activity of Kaffir Lime Peel Extract against Streptococcus mutans}

\author{
Rosalie M.W. Purwanto, Jeni Pabontong, Ery S. Retnoningtyas, and Wenny Irawaty*) \\ Chemical Engineering Department, Faculty of Engineering, Widya Mandala Catholic University Surabaya \\ J1. Kalijudan 37 Surabaya 60114
}

*) Corresponding author: wenny_i_s@ukwms.ac.id

(Received: April 23, 2018 Accepted: December 10, 2018)

\begin{abstract}
Kaffir lime peels contain polyphenols as natural antioxidant and antimicrobial agent. The aims of this study were to (1) extract phenolics compounds from kaffir lime peels using water, ethanol 70\% and ethanol $96 \%$ as the solvent, and (2) assess the antibacterial activity of the extract against Streptococcus mutans which is the main cause of dental caries. Research methodology includes preparation and extraction of polyphenols from kaffir lime peels, preparation of mouthwash based-kaffir lime peels extracts and evaluation the mouthwash ability to inhibit the growth of Streptococcus mutans. The results show water exhibited the best solvent to extract polyphenols among the three solvents. The total phenolics content in the water extract was observed at $11.42 \pm 0.48 \mathrm{mg} \mathrm{GAE} / \mathrm{g}$, whilst in the two ethanolic extracts were $10.91 \pm 0.87$ and $8.87 \pm 0.53 \mathrm{mg}$ GAE/g for ethanol 70 and $96 \%$, respectively. Consequently, the water-based extract performed the highest antimicrobial activity. The highest inhibition zone was demonstrated by $100 \%$ extract of concentration extract variation. Although the inhibition zone of the mouthwash was smaller than the commercial product, the extract has the potential to be developed as a safe mouthwash for long-term usage.
\end{abstract}

Keywords: dental caries; kaffir lime; mouthwash; peel; phenolic; Streptococcus mutans

How to Cite This Article: Purwanto, R.M.W., Pabontong, J., Retnoningtyas, E.S., and Irawaty, W. (2018), Antimicrobial Activity of Kaffir Lime Peel Extract against Streptococcus mutans, Reaktor, 18(4), 235-240, http://dx.doi.org/10.14710/reaktor.18.04.235-240.

\section{INTRODUCTION}

Dental and oral health are common problems faced by both children and adults (Marsh and Martin, 2009). Periodontitis is a gum inflammation that involves periodontium tissue that surrounds and support teeth, namely the periodontal ligament and alveolar bone (Pihlstrom et al., 2005). Periodontitis occurs due to disruption of oral microbial ecosystem balance by some gram-negative anaerobic bacteria
(Figure 1.) (Cheng et al., 2017; Marsh and Martin, 2009). Moreover, periodontitis is claimed to trigger degenerative diseases such as heart, diabetes, osteoporosis, pneumonia, arthritis and low preterm birth weight (Cheng et al., 2017; Otomo-Corgel et al., 2012).

Communities with periodontitis tend to have dental caries (Mattila et al., 2010), known as cavities, due to the dissolution of the enamel layer. Destruction 


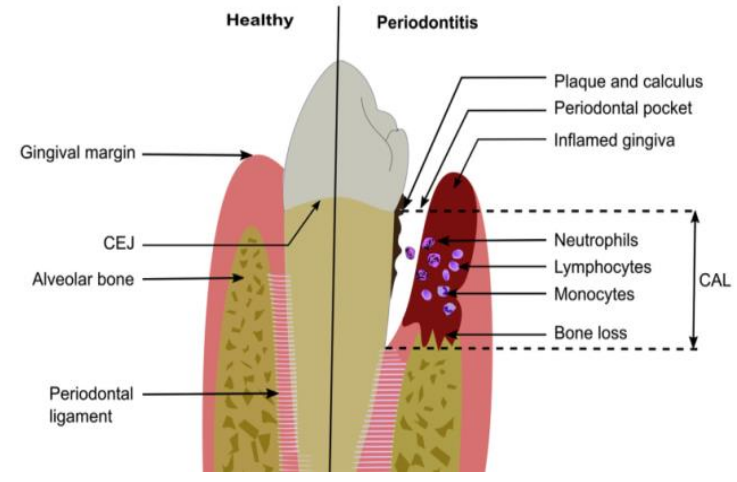

Figure 1. Illustration of periodontitis (Cheng et al., 2017)

to the enamel layer is due to the presence of acid released by bacteria present in dental plaque. One of the bacteria that causes dental caries is Streptococcus mutans (Loesche, 1986). One technique to inhibit dental caries is the use of mouthwash regularly. It has been believed that fluoride-containing mouthwash reduces the formation of dental plaque and dental caries (Roberts et al., 1948).

Mouthwash solution consists of active ingredient and alcohol as the carrier of the active ingredient. Additional compounds such as sweetener, surfactant, coloring agent and therapeutic materials are also incorporated (Crowley, 2006; Volpe, 1997). However, the presence of alcohol can cause dryness, initial burning sensation, and unpleasant taste. Dry mouth will lead to more complications such as additional dental cavities and infection of the salivary glands since the saliva is a natural antibacterial agent (Hart and Powell, 1990). Consequently, the use of alcohol over a relatively long period will disturb the health of the oral cavity (Vlachojannis et al., 2012). Non-alcohol mouthwash offers benefits especially for long-term implementation.

Drug, essential oil or their mixture could be the active ingredients in mouthwash which exhibit antibacterial activity. This study focuses on the active ingredients obtained from plants as antibacterial agents. The addition of essential oils to the mouth rinses was reported to reduce the formation of biofilm layers on tooth surfaces (Fine et al., 2001; Quintas et al., 2015; Riep et al., 1999). In other words, the occurrence of dental caries can be reduced by adding essential oils or plant extract in oral health products. Clinical trials performed by Riep et al. (1990) suggest that the addition of essential oils to mouthwash demonstrates greater effect as anti dental agents than fluoride-containing mouthwash (Riep et al., 1999). The addition of essential oils of plant extracts (turmeric and green tea) was reported to have antibacterial properties against oral microbes (Fournier-Larente et al., 2016; Lee et al., 2017). The antibacterial activities of plants or their extracts are claimed due to the presence of phenolics, flavonoids and other compounds as their secondary metabolic products during growth processing.

Kaffir lime is not widely utilized since the fruit is unpleasant and contains a certain amount of phenolics, flavonoids, and other compounds (Bocco et al., 1998; Orak et al., 2012). Kaffir lime peel contains phenolics, flavonoids, alkaloids, saponins, and tannins (Irawaty and Ayucitra, 2015). The compounds are claimed to have antibacterial activity against $E$. coli, $S$. mutans, S. aureus, B. cereus, and P. aeruginosa (Klangpetch et al., 2016; Olchowik-Grabarek et al., 2014; Rodríguez-Pérez et al., 2016). Some of the bacteria are reported as the main causes of dental caries (Marsh and Martin, 2009). The fruit peel is reported to exhibit higher antioxidant activity compared to that of the fruit juice and seeds (Derakhshan et al., 2018; Orak et al., 2012; Wolfe et al., 2003).

Although several studies have been carried out to assess the antibacterial abilities of citrus peel extracts (Baba et al., 2016; Min et al., 2014; Sultana et al., 2012), however, the study of essential oils and the extracts of kaffir lime peel tested on E. coli, $S$. typhimurium, B. cereus, Xanthomonas oryzae, and $S$. aureus (Chanthaphon et al., 2008; Raksa et al., 2017; Singh et al., 2018) is still limited. The main aim of this study was to utilize the kaffir lime peel to be an active ingredient in mouthwash to prevent dental caries and employ the extract as a natural antibacterial agent against $S$. mutans to prevent dental caries.

\section{RESEARCH METHODS \\ Extraction}

Fresh and undamaged kaffir lime fruits were obtained from Keputran market Surabaya in January 2017. Firstly, the fruits were peeled and cut to obtain a size around $5 \times 5 \mathrm{~mm}$, then the peels were dried in an oven at $35^{\circ} \mathrm{C}$ for $48 \mathrm{~h}$ to obtain the water content is less than $10 \%$. Dried peels were stored in an airtight zip bag for future use. Secondly, phenolics of kaffir lime peels were extracted by using the maceration technique at room temperature for $8 \mathrm{~h}$. Water, ethanol $70 \%$, and ethanol $96 \%$ were selected as the solvents. After the extraction process was complete, the solid part was separated. Then the ethanol was vaporized using a rotary evaporator (IKA, RV-10) at $45^{\circ} \mathrm{C}$.

\section{Total Phenolic Content Determination}

Total phenolic content in extracts was determined according to the procedure of Anagnostopoulou et al. (2006) with slight modification. Briefly, $0.2 \mathrm{~mL}$ of extract was added to $1.8 \mathrm{~mL}$ of water and $1 \mathrm{~mL}$ of Folin-Ciocalteu reagent (1:10), followed by the addition of $3 \mathrm{~mL}$ of sodium carbonate solution $6 \%(\mathrm{w} / \mathrm{v})$, the mixture was allowed to stand for $1 \mathrm{~min}$ at room temperature and dark condition followed with incubation at room temperatura for $30 \mathrm{~min}$ for color development. The solution absorbance was measured using a UV-Vis spectrophotometer (Shimadzu, UV mini) at $730 \mathrm{~nm}$. 
Gallic acid was used as the standard compound, and the total phenolic content was expressed as milligram of Gallic Acid Equivalent (GAE) per gram of dry peels.

\section{Preparation of Mouthwash Solution}

Solution A was prepared by mixing tween 80 and water with a ratio of $1: 10(\mathrm{w} / \mathrm{v})$ followed with glycerin $(1.25 \mathrm{~mL})$ and $3 \mathrm{~mL}$ of sodium saccharin. Meanwhile, solution B consisted of kaffir lime peel extract $8 \%$ and $0.5 \mathrm{~mL}$ of peppermint oil with a ratio of $1: 12$. The mouthwash solution was obtained after mixing solution A and B with a volume ratio of 10:1.

\section{Antibacterial Assay}

Antibacterial activity assessment of the extracts was determined by using the diffusion disk method. First, the suspension of $S$. mutans was applied on BHI-Agar medium by using a sterile lid cotton. Second, the sterilized test paper (diameter $6 \mathrm{~mm}$ ) was dipped into the test extract solution which prepared in various concentration $(25,50,75$ and $100 \% \mathrm{v} / \mathrm{v})$. Third, the test paper was placed on top of the agar medium and incubated at $37^{\circ} \mathrm{C}$ for $24 \mathrm{~h}$. Clear areas around the test paper indicated the ability of the extract to inhibit the growth of the selected bacteria. The procedure was repeated using wáter extract-based mouthwash and commercial mouthwash as the positive control.

\section{RESULTS AND DISCUSSIONS \\ Total Phenolic Content}

Total phenolic content of the three extracts is presented in Figure 1. As seen, type of solvent used to extract kaffir lime peels influences the number of phenolics extracted from kaffir lime peels. The phenolic content in the extract of water, $70 \%$ ethanol and $96 \%$ ethanol was found $11.42 \pm 0.48 ; 10.91 \pm$ 0.87 , and $8.87 \pm 0.53 \mathrm{mg} \mathrm{GAE} / \mathrm{g}$, respectively. After processing, the amount of phenolic content detected in the water- and ethanol 70\%-based extract was observed similar. On the other hand, (Chan et al., 2009) showed that the increase of ethanol concentration up to $60 \%$ has increased the total phenolics content extracted from kaffir lime peels. This different result can be explained by temperature treatment applied to our extracts. Following the extraction, the extract was further heated to remove ethanol. This treatment may decrease the amount of phenolics since some of phenolic compounds are sensitive to temperature. The employment of ethanol $96 \%$ provides lower amount of phenolics by a factor up to 0.8 compared to other extracts. Similar trend was reported previously (Chan et al., 2009). This result indicates the concentration of ethanol, in another word is solvent polarity, affects the extraction of phenolic compounds which in turn affecting the total phenolic contents can be extracted from the peels. The exploration of other solvents possess different polarities such as hexane, acetone or ethyl acetate may provide different amount of phenolic content (Safdar et al., 2017). However, other solvents was not applied in this study due to the safety matter of the product for oral health.

\section{Antibacterial Activity}

The ability of extracts to inhibit the growth of $S$. mutans, which presented as the inhibitory zone diameter, is shown in Figure 2. It can be seen from Figure 2 that the three extracts demonstrated certain activity against $S$. mutans. The water extract possesses the highest inhibitory zone diameter compared to the other extracts in the same concentration. For the $50 \%$ extract test solution, the inhibitory zone diameter of the water extracts reached $7.75 \pm 0.35 \mathrm{~mm}$, while the extracts of ethanol $70 \%$ and ethanol $96 \%$ were $6.0 \pm$ 0.71 and $5.50 \pm 0.71 \mathrm{~mm}$, respectively. The same trend was also observed for other extract concentrations in the tested solution.

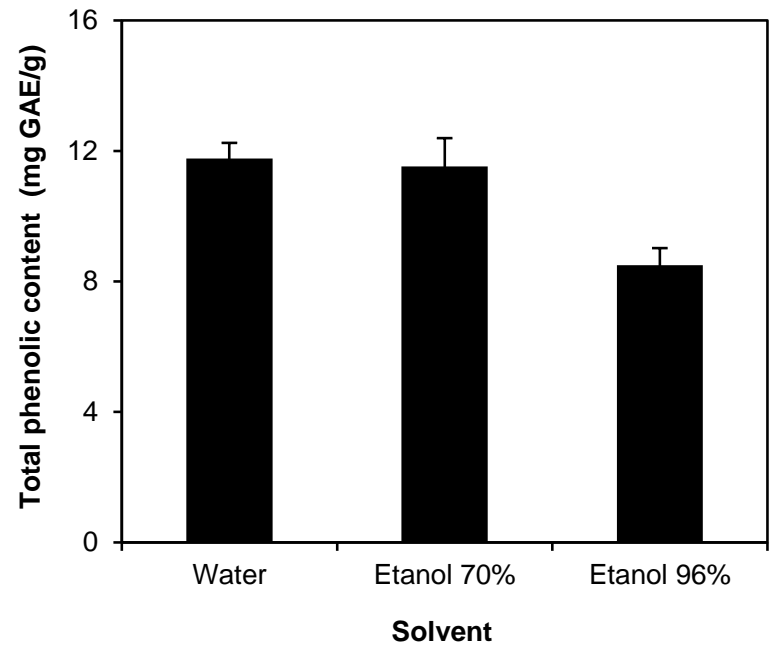

Figure 1. The effect of solvent on total phenolic extracted from kaffir lime peels

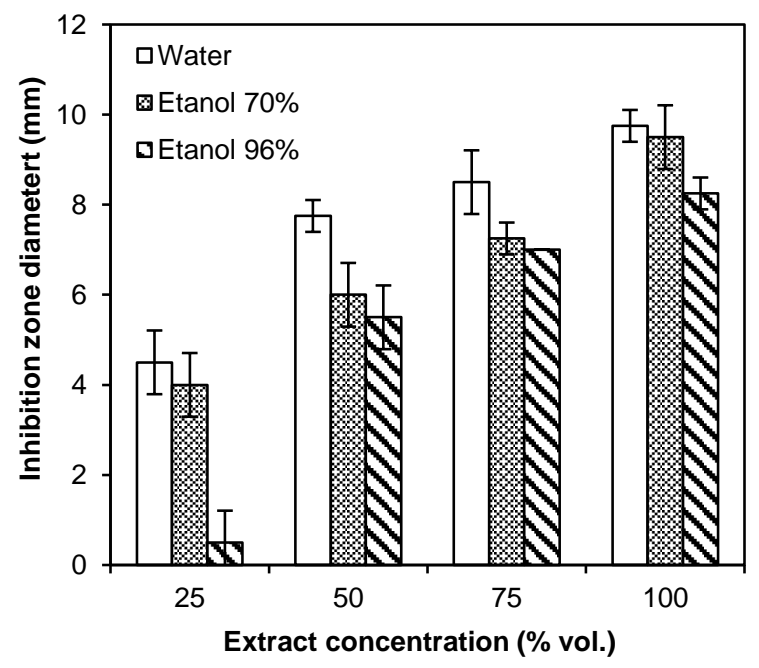

Figure 2. Antibacterial activity of kaffir lime peel extracts 
The performance of water extract to inhibit $S$. mutans can be explained by the highest amount of phenolics in the water extract compared to the other two extracts (Figure 1). Phenolics compounds such as catechin, epicatechin and gallic acid are claimed to have antibacterial properties (Cueva et al., 2010; Ouerghemmi et al., 2017). Those compounds were detected in kaffir lime peels (Wijaya et al., 2017). Therefore, it is not surprising if the water extract demonstrated the highest antibacterial activity against the tested bacteria since it contains the highest phenolics compounds among the three extracts.

Figure 2 shows the inhibition zone diameter was greater with the increase of the extract concentration. This can be explained by the increase of phenolics in the test solution by increasing the extract concentration. As previously described that phenolics possess antibacterial properties and thus, the increase of the extract concentration promotes higher antibacterial activity. The effect of the extract dose on antibacterial activity was also reported on essential oil of onion as reported by (Benkeblia, 2004).

In order to apply the extract as the main ingredient of mouthwash solution, the water extract is added to basic mouthwash solution. Then the solution was tested for its activity against $S$. mutans. The ability of the mouthwash solution to inhibiting the growth of $S$. mutans is presented as the inhibiton zone diameter as shown in Figure 3.

Figure 3 shows the prepared mouthwash with active ingredient of the water extract provided $2 \mathrm{~mm}$ inhibition zone diameter, while the positive control has 2 times greater of inhibition diameter. Commercial mouthwash solution contains alcohol which is an antiseptic agent and therefore, it has greater ability to retard the growth of $S$. mutans. This result shows a promising application of the water extract of kaffir lime peels to be added into mouthwash solution. In addition, the use of natural extract can reduce problems faced from the use of alcohol-containing mouthwash such as mouth dryness that promotes the unbalanced mouth flora.

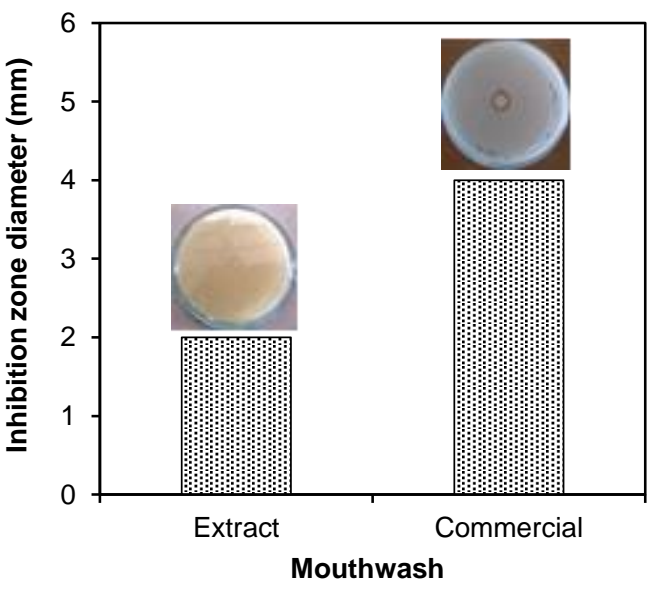

Figure 3. Antibacterial activity of the extract-based and commercial mouthwash

\section{CONCLUSION}

Based on the results, it can be concluded that solvent polarity influenced the number of phenolic compounds extracted from kaffir lime peels. The water extract possesses the highest phenolic content and thus, exhibits the highest antibacterial activity againts $S$. mutans. The use of pure water extract provides the greatest inhibitory diameter zone. Although the antibacterial activity of kaffir lime peel extract-based mouthwash was observed lower than commercial mouthwash, it potent to be further developed by taking into account the safety factor for long-term use.

\section{ACKNOWLEDGMENT}

This study was funded by Direktorat Jenderal Pembelajaran dan Kemahasiswaan (DITLITABMAS) Kementerian Riset, Teknologi, dan Pendidikan Tinggi (RISTEKDIKTI) through student research grant (Program Kreativitas Mahasiswa - Penelitian) 2017.

\section{REFERENCES}

Anagnostopoulou, M.A., Kefalas, P., Papageorgiou, V.P., Assimopoulou, A.N., and Boskou, D., (2006), Radical Scavenging Activity of Various Extracts and Fractions of Sweet Orange Peel (Citrus Sinensis), Food Chemistry, 94, pp. 19-25.

Baba, E., Acar, Ü., Öntaş, C., Kesbiç, O.S., and Yilmaz, S., (2016), Evaluation of Citrus Limon Peels Essential Oil on Growth Performance, Immune Response of Mozambique Tilapia Oreochromis Mossambicus Challenged with Edwardsiella Tarda, Aquaculture, 465, pp. 13-18.

Benkeblia, N., (2004), Antimicrobial Activity of Essential Oil Extracts of Various Onions (Allium Cepa) and Garlic (Allium Sativum), Lebensm.-Wiss. u.-Technol., 37, pp. 263-268.

Bocco, A., Cuvelier, M.-E., Richard, H., and Berset, C., (1998), Antioxidant Activity and Phenolic Composition of Citrus Peel and Seed Extract, Journal of Agricultural and Food Chemistry, 46(6), pp. 21232129.

Chan, S.W., Lee, C.Y., Yap, C.F., Aida, W.M.W., and Ho, C.W., (2009), Optimisation of Extraction Conditions for Phenolic Compounds from Limau Purut (Citrus Hystrix) Peels, International Food Research Journal, 16, pp. 203-213.

Chanthaphon, S., Chanthachum, S., and Hongpattarakere, T., (2008), Antimicrobial Activities of Essential Oils and Crude Extracts from Tropical Citrus Spp. Against Food-Related Microorganisms, Songklanakarin Journal of Science and Technology, 30(Suppl. 1), pp. 125-131. 
Cheng, Z., Meade, J., Mankia, K., Emery, P., and Devine, D.A., (2017), Periodontal Disease and Periodontal Bacteria as Triggers for Rheumatoid Arthritis, Best Practice \& Research Clinical Rheumatology, 31(1), pp. 19-30.

Crowley, M.M., (2006). Solutions, Emulsions, Suspensions, and Extracts. In D.B. Troy, \& P. Beringer (Eds.), Remington: The Science and Practice of Pharmacy, Lippincott Williams \& Wilkins, USA, p. 21.

Cueva, C., Moreno-Arribas, M.V., Martín-Álvarez, P.J., Bills, G., Vicente, M.F., Basilio, A., Rivas, C.L., Requena, T., Rodríguez, J.M., and Bartolomé, B., (2010), Antimicrobial Activity of Phenolic Acids against Commensal, Probiotic and Pathogenic Bacteria, Research in Microbiology, 161(5), pp. 372382.

Derakhshan, Z., Ferrante, M., Tadi, M., Ansarie, F., Heydari, A., Hosseini, M.S., Conti, G.O., and Sadarabad, E.K., (2018), Antioxidant Activity and Total Phenolic Content of Ethanolic Extract of Pomegranate Peels, Juice and Seeds, Food and Chemical Toxicology, 114, pp.108-111.

Fine, D.H., Furgang, D., Barnett, M.L., Drew, C., Steinberg, L., Charles, C., and Vincent, J.W., (2001), Effect of an Essential Oilcontaining Antiseptic Mouthrinse on Plaque and Salivary Streptococcus Mutans Levels, Journal of Clinical Periodontology, 27(3), pp. 157-161.

Fournier-Larente, J., Morin, M.-P., and Grenier, D., (2016), Green Tea Catechins Potentiate the Effect of Antibiotics and Modulate Adherence and Gene Expression in Porphyromonas Gingivalis, Archives of Oral Biology, 65, pp. 35-43.

Hart, B.L., and Powell, K.L., (1990), Antibacterial Properties of Saliva: Role in Maternal Periparturient Grooming and in Licking Wounds, Physiology \& Behavior, 48(3), pp. 383-386.

Irawaty, W., and Ayucitra, A. (2015). Effect of Solvent Polarity on Antioxidant Activity during Fractionation of Ethanolic Extract of Citrus hystrix Peel. The 3rd Bali International Seminar on Science and Technology. Bali.

Klangpetch, W., Phromsurin, K., Hannarong, K., Wichaphon, J., and Rungchang, S., (2016), Antibacterial and Antioxidant Effects of Tropical Citrus Peel Extracts to Improve the Shelf Life of Raw Chicken Drumettes, International Food Research Journal, 23(2), pp. 700-706.

Lee, H.-J., Kang, S.-M., Jeong, S.-H., Chung, K.-H., and Kim, B.-I., (2017), Antibacterial Photodynamic
Therapy with Curcumin and Curcuma Xanthorrhiza Extract against Streptococcus Mutans, Photodiagnosis and Photodynamic Therapy, 20, pp. 116-119.

Loesche, W.J., (1986), Role of Streptococcus Mutans in Human Dental Decay, Microbial Reviews, 50(4), pp. 353-380.

Marsh, P.D., and Martin, M.V., (2009), Oral Microbiology, 5, Elsevier, Edinburgh.

Mattila, P.T., Niskanen, M.C., Vehkalahti, M.M., Nordblad, A., and Knuuttila, M.L.E., (2010), Prevalence and Simultaneous Occurrence of Periodontitis and Dental Caries, Journal of Clinical Periodontology, 37(11), pp. 962-967.

Min, K.Y., Kim, H.J., Lee, K.A., Kim, K.-T., and Paik, H.-D., (2014), Antimicrobial Activity of AcidHydrolyzed Citrus Unshiu Peel Extract in Milk, Journal of Dairy Science, 97(4), pp. 1955-1960.

Olchowik-Grabarek, E., Swiecicka, I., AndreevaKovaleskaya, Z., Solonin, A., Bonarska-Kujawa, D., Kleszczyńska, H., Mavlyanov, S., and Zamaraeva, M., (2014), Role of Structural Changes Induced in Biological Membranes by Hydrolysable Tannins from Sumac Leaves (Rhus Typhina L.) in Their Antihemolytic and Antibacterial Effects, The Journal of Membrane Biology, 247(6), pp. 533-540.

Orak, H.H., Yagar, H., and Isbilir, S.S., (2012), Comparison of Antioxidant Activities of Juice, Peel, and Seed of Pomegranate (Punica Granatum L.) and Inter-Relationships with Total Phenolic, Tannin, Anthocyanin, and Flavonoid Contents, Food Science and Biotechnology, 21(2), pp. 373-387.

Otomo-Corgel, J., Pucher, J.J., Rethman, M.P., and Reynolds, M.A., (2012), State of the Science: Chronic Periodontitis and Systemic Health, Journal of Evidence-Based Dental Practice Special Issue Periodontal and Implant Treatment, 12(S1), pp. 2028

Ouerghemmi, I., Rebey, I.B., Rahali, F.Z., Bourgou, S., Pistelli, L., Ksouri, R., Marzouk, B., and Tounsi, M.S., (2017), Antioxidant and Antimicrobial Phenolic Compounds from Extracts of Cultivated and WildGrown Tunisian Ruta Chalepensis, Journal of Food and Drug Analysis, 25(2), pp. 350-359.

Pihlstrom, B.L., Michalowicz, B.S., and Johnson, N.W., (2005), Periodontal Diseases, Lancet, 366(9499), pp. 1809-1820.

Quintas, V., Prada-López, I., Prados-Frutos, J.C., and Tomás, I., (2015), In Situ Antimicrobial Activity on Oral Biofilm: Essential Oils vs 0.2\% Chlorhexidine, Clinical Oral Investigations, 19(1), pp. 97-107. 
Raksa, A., Sawaddee, P., Raksa, P., and Aldred, A.K., (2017), Microencapsulation, Chemical Characterization, and Antibacterial Activity of Citrus Hystrix Dc (Kaffir Lime) Peel Essential Oil, Monatshefte für Chemie, 148(7), pp. 1229-1234.

Riep, B.G., Bernimoulin, J.P., and Barnett, M.L., (1999), Comparative Antiplaque Effectiveness of an Essential Oil and an Amine Fluoride/Stannous Fluoride Mouthrinse, Journal of Clinical Periodontology, 26(3), pp. 164-168.

Roberts, J.F., Bibby, B.G., and Wellock, W.D., (1948), The Effect of Acidulated Fluoride Mouthwash on Dental Caries, Journal of Dental Research, 27(4), pp. 497-500.

Rodríguez-Pérez, C., Quirantes-Piné, R., Uberos, J., Jiménez-Sánchez, C., Peña, A., and Segura-Carretero, A., (2016), Antibacterial Activity of Isolated Phenolic Compounds from Cranberry (Vaccinium Macrocarpon) against Escherichia Coli, Food \& Function, 7(3), pp. 1564-1573.

Safdar, M.N., Kausar, T., Jabbar, S., Mumtaz, A., Ahad, K., and Saddozai, A.A., (2017), Extraction and Quantification of Polyphenols from Kinnow (Citrus Reticulate L.) Peel using Ultrasound and Maceration Techniques, Journal of Food and Drug Analysis, 25, pp. $488-500$.
Singh, A., Gupta, R., Tandon, S., Prateeksha, and Pandey, R., (2018), Anti-Biofilm and Anti-Virulence Potential of 3, 7-Dimethyloct-6-2 Enal Derived from Citrus Hystrix against Bacterial Blight of Rice Caused by Xanthomonas Oryzae Pv. Oryzae, Microbial Pathogenesis, 115, pp. 264-271.

Sultana, H.S., Ali, M., and Panda, B.P., (2012), Influence of Volatile Constituents of Fruit Peels of Citrus Reticulata Blanco on Clinically Isolated Pathogenic Microorganisms under in-Vitro, Asian Pacific Journal of Tropical Biomedicine, 2(3), pp. s1299-s1302.

Vlachojannis, C., Winsauer, H., and Chrubasik, S., (2012), Effectiveness and Safety of a Mouthwash Containing Essential Oil Ingredients, Phytotherapy Research, 27(5), pp. 685-691.

Volpe, A.R., (1997). Dentrifices and Mouthrinses. In R.C. Caldwell, \& R.E. Stallard (Eds.), A Text Book of Preventive Dentistry, Saunders Co., Philadelphia, pp. $175,183$.

Wijaya, Y.A., Widyadinata, D., Irawaty, W., and Ayucitra, A., Reaktor, 17(3), pp. 111-117.

Wolfe, K., Wu, X., and Liu, R.H., (2003), Antioxidant Activity of Apple Peels, Journal of Agricultural and Food Chemistry, 51(3), pp. 609-614. 